\title{
Drinking Water Quality Governance: A Comparative Case Study of Brazil, Ecuador, and Malawi
}

\author{
Georgia L. Kaysera,b, Urooj Amjad ${ }^{a, c}$, Fernanda Dalcanale ${ }^{a}$, Jamie Bartram ${ }^{a}$, and Margaret \\ E. Bentley ${ }^{d}$ \\ aThe Water Institute, The Department of Environmental Science and Engineering, The Gillings \\ School of Global Public Health University of North Carolina at Chapel Hill, 27599-7431, USA \\ 'Global Research Institute University of North Carolina at Chapel Hill, 27599-7431, USA \\ dDepartment of Nutrition The Gillings School of Global Public Health University of North Carolina \\ at Chapel Hill, 27599-7431, USA
}

\begin{abstract}
Human health is greatly affected by inadequate access to sufficient and safe drinking water, especially in low and middle-income countries. Drinking water governance improvements may be one way to better drinking water quality. Over the past decade, many projects and international organizations have been dedicated to water governance; however, water governance in the drinking water sector is understudied and how to improve water governance remains unclear. We analyze drinking water governance challenges in three countries-Brazil, Ecuador, and Malawias perceived by government, service providers, and civil society organizations. A mixed methods approach was used: a clustering model was used for country selection and qualitative semistructured interviews were used with direct observation in data collection. The clustering model integrated political, economic, social and environmental variables that impact water sector performance, to group countries. Brazil, Ecuador and Malawi were selected with the model so as to enhance the generalizability of the results. This comparative case study is important because similar challenges are identified in the drinking water sectors of each country; while, the countries represent diverse socio-economic and political contexts, and the selection process provides generalizability to our results. We find that access to safe water could be improved if certain water governance challenges were addressed: coordination and data sharing between ministries that deal with drinking water services; monitoring and enforcement of water quality laws; and sufficient technical capacity to improve administrative and technical management of water services at the local level. From an analysis of our field research, we also developed a conceptual framework that
\end{abstract}

\footnotetext{
(C) 2014 Published by Elsevier Ltd.

This manuscript version is made available under the CC BY-NC-ND 4.0 license.

${ }^{\mathrm{b}}$ The Department of Public Policy University of North Carolina at Chapel Hill, 27599-7431, USA gkayser@ unc.edu, Ph: (919) 966-7319.

Publisher's Disclaimer: This is a PDF file of an unedited manuscript that has been accepted for publication. As a service to our customers we are providing this early version of the manuscript. The manuscript will undergo copyediting, typesetting, and review of the resulting proof before it is published in its final citable form. Please note that during the production process errors may be discovered which could affect the content, and all legal disclaimers that apply to the journal pertain.
} 
identifies policy levers that could be used to influence governance of drinking water quality on national and sub-national levels, and the relationships between these levers.

\section{Keywords}

water governance; drinking water quality; comparative case study; conceptual framework; technical assistance

\section{Introduction}

Inadequate access to sufficient and safe drinking water is one of the main causes of 842,000 deaths and billions of cases of diarrheal disease per year (Clasen et al., 2014). This has direct impacts on public health, and the effects are greatest on children under-five (Hunter et al., 2010; Haller et al., 2007). Over the past century, many technological advances have been made to improve the protection of water sources and the treatment of water for drinking; however, many countries still face obstacles that reduce their ability to ensure the delivery of safe drinking water over time, and throughout the country (Lee and Schwab, 2005; Hunter et al, 2009; Rizak and Hrudey, 2008). Water governance 'failures' may explain some of the obstacles (Tortajada, 2010; Bakker et al., 2008; Rogers and Hall, 2003; GWP, 2000; UNDP, 2010).

After more than a decade of water governance research, however, water governance is still an umbrella concept and how to improve it is unclear (Biswas and Tortajada 2010; Tortajada 2010b; Lautze et al. 2011). Water governance is concerned with how institutions operate and how regulations affect political actions and societal concerns through formal and informal instruments (UNDESA et al, 2003), and is meant to enable practical management tools to be applied (Tortajada, 2010). The focus of water governance research is often on broad theoretical concepts of transparency, equity, and accountability (Rogers and Hall, 2003), thematic concepts of Integrated Water Resources Management (Parkes et al, 2010; PahlWostl et al., 2012; Ison et al., 2007), water security and transboundary water management (Wolf et al., 2003; Allan 2002; Mirumachi and van Wyk 2010; Zeitoun, et al 2011), and the global effects of climate change on water management (Schluter et al, 2010; Bisaro et al, 2010; Kranz et al, 2010). While a few conceptual frameworks and empirical studies provide a basis for analyzing water management policy (Pahl-Wostl et al, 2010; Knieper et al., 2010; Franks and Cleaver, 2007), there is very little theoretical analysis and debate on the core concepts of water governance, (Franks and Cleaver, 2007; Tortajada, 2010), especially water quality governance. There are numerous studies in the public health and engineering fields on drinking water supply and how to improve it. The research in these fields has focused on the study of technical water management challenges and the study of specific interventions -household water treatment and safe storage, source water protection, and water safety plans - and their impact on public health or drinking water quality for example (Fewtrell et al., 2005). Few studies have attempted to look at governance failures in drinking water supply in single cities or country cases (Bakker et al, 2008; Johnson and Hadmer, 2002; Fuest and Haffner, 2007), and a recent case study compared the institutions, roles and responsibilities that guide the drinking water sector in nine countries (Rahman et al., 2011). 
What is missing in the research and policy debate is contextualized analysis of drinking water quality governance (DWQGo) across countries so as to decrease the disease burden, improve public health, and sustain services over time.

In this article, we revisit the theory and practice of water governance by examining drinking water governance challenges in three countries-Brazil, Ecuador, and Malawi. Using mixed methods, water governance challenges and their influence on drinking water management or service delivery are explored. The data were used to develop a conceptual framework for identifying challenges in the governance of drinking water quality on national and subnational levels, and the relationships between these challenges.

\section{Methods}

\subsection{Ethics}

The University of North Carolina Institutional Review board reviewed this study and approved the protocol on 28 September 2011.

\subsection{Research Design and Analysis}

A country clustering model was used for country case selection and a snowball sample was used in each country to select interviewees for semi-structured in-depth interviews and focus groups.

To select country cases for study, a country clustering model was used that incorporates variables connected to performance in the water, sanitation, and hygiene sector (WaSH) (Onda et al., 2014). The model groups countries into five clusters based on similarities and differences across variables (political, economic, social and environmental) that impact WASH performance. Variables in the cluster model and the data for each country are represented in Table 1. Brazil, Ecuador and Malawi were selected from three of five clusters in the model. The use of the model is more sophisticated and provides more rigorous reliability than simply using geography or GDP for country case selection. The use of the country clustering model to select country cases, also enhances the representation and generalizability of our study.

After, selecting countries and prior to initiation of the field research, a brief literature review of drinking water quality laws, policies, and governing institutions in the sector was conducted in each country.

Field research took place from February through June 2012. In each country, a snowball sample was used to select individuals for interview. Interviewees included representatives from government, non-governmental organizations (NGOs), international organizations (IOs), and water service providers. Initial contact with government officials, NGOs and IOs in each country capital was made after discussion with researchers who conducted research in these countries (Rahman et al., 2011). Interviews lasted between 20 minutes and one working day. Interviews with national and provincial level government, NGO and IO representatives included questions about regulations, monitoring and enforcement, and obstacles in the delivery of safe drinking water. To have representation of service provision, 
provincial and national-level government officials were asked for a list of particularly wellfunctioning drinking water systems in the country and others with significant challenges in operation and or management. Water systems were then visited and interviews were conducted with water service providers and managers (operators, utility managers or presidents of community elected water committees). Interviews with water service providers included questions around water quantity, water quality, treatment, management, financing, and technical assistance. Observations of functioning water systems, treatment plants, and laboratories were also conducted. A total of 63 interviews were conducted in Brazil, Ecuador and Malawi. Table 2 describes the representatives interviewed in each country.

In Brazil, the States of São Paulo, Ceará, Santa Catarina, and Mato Grosso were visited and interviews conducted. In Ecuador, the provinces of Azuay, Pichincha, Riobamba, Esmeraldas, and Loja were visited and interviews conducted. In Malawi, the districts of Lilongwe, Kasungu, Blantyre, and Zomba were visited and interviews conducted.

Data were analyzed, as a team. Data were analyzed iteratively so that themes could emerge. The interview transcripts were viewed and analyzed in NVivo 9, a qualitative data analysis software package used to organize and make notations for analysis, and by reading through the interviews to identify common challenges or themes. Three different coders identified common themes, separately. Each challenge that was consistently mentioned in interviews was classified as a node and the relationships between these nodes became links.

The codes were revisited to understand the common challenges and common links in all three countries. A conceptual framework emerged from this process. The water governance entity that has influence on each of these nodes was then identified in the data, and placed in the background of the framework, so as to identify the institutions that have influence over specific challenges. DWQGo policy levers are, thus, identified in the framework. A literature review and interdisciplinary systems thinking were facilitated to triangulate the findings.

\section{Results}

\subsection{Water Quality Laws and Policies}

In Brazil, DWQGo is shared between the Ministry of Health $(\mathrm{MoH})$ and the Ministry of Cities. The MoH regulates water quality standards. The Ministry of Cities creates regulations, provides guidelines, and financial resources for infrastructure. The municipalities, however, hold the rights to grant concessions for water and sanitation services to a public, private or public-private company. In the 1970s, municipalities granted concessions for services to public, state-owned companies, as part of a plan by the government to expand services (PLANASA). In the 1990s, there was a push for privatization of state-owned services, including water and sanitation. The lack of a regulatory framework and public opposition to rising prices prevented the same scale of privatization in water and sanitation services that occurred in other sectors (telephone and electricity). Most municipalities are still served by private-public companies, where the state is the majority shareholder. There are 3856 municipalities served private-public companies, 1510 municipal run services, and 499 privately run companies (National Water Agency of 
Brazil). One of the largest public-private companies in the world is SABESP, serving 27.6 million people in Sao Paulo. It had revenues of US \$2.6 billion in 2011, and stocks in the company are traded on the Brazilian (BOVESPA) and NY stock exchange (SABESP, 2012).

In Ecuador, DWQGo is shared by the Ministry of Urban Development and Housing (MIDUVI), the Ministry of Health (MoH), and the National Secretary of Water (SENAGUA). Municipal governments, however, are responsible for water service delivery in urban and rural areas. In most provinces, the municipality provides water to the provincial capital city. In rural areas, community water committees (Juntas de Agua), elected by the community, are responsible for service delivery administration. Operators are hired to operate and maintain the system, and ensure service delivery and treatment (if applied). Community members in rural and urban areas pay tariffs that cover the operating costs and capital expenditures of the water service delivery. Municipal governments are responsible for seeing that the delivery occurs. The $\mathrm{MoH}$, through their provincial health departments, is responsible for surveillance of water quality. They provide some technical support to community water committees. MIDUVI is responsible for developing drinking water standards, policies, guidelines, and determines the sector's development strategy. MIDUVI technicians in each provincial capital provide technical assistance to the municipalities. SENAGUA has a mission to be a steward of water resources in the country and to develop integrated water resources management within the country. SENAGUA gives authorization for use of a particular water source for drinking or irrigation, and is responsible for testing the water quality of those sources.

In Malawi, DWQGo is the responsibility of the Ministry of Irrigation and Water Development (MoIWD) and the National Water Resources Board. MoIWD is responsible for water sector policy, service provision, regulation, and surveillance in the country (Rahman et al, 2011). MoIWD manages water services in the urban areas through five water boards-Lilongwe, Blantyre, Northern, Central, and Southern. The Malawi government appoints the head of each water board. The Water Boards have some independence in decision-making. In rural areas, district assemblies, private contractors and NGOs provide water to communities (Rahman et al, 2011; Mulwafu et al, 2003).

All countries have laws that define which entity is responsible for specific aspects of water service delivery, monitoring, enforcement, and surveillance. All three countries have water quality standards, and watershed or catchment area policies to protect water resources.

\subsection{Common Challenges in Drinking Water Quality Governance}

The interviews and field observation in Brazil, Ecuador and Malawi allowed us to identify common DWQGo challenges. They include: lack of coordination and data sharing between ministries, inadequate monitoring, enforcement and surveillance of water quality laws, insufficient technical capacity for water quality testing in rural areas, scarce financial resources, and inadequate administrative and technical management of water systems. The analysis of the common challenges in water governance identified in the semi-structured interviews is reviewed below and direct quotes or summaries of quotes are provided with the type of organization for which the interviewee works. 
3.2.1. Agency Coordination and Data-sharing-In Brazil and Ecuador, government officials suggested that improved coordination and data sharing would increase transparency, and decrease duplication of efforts. While, data sharing and coordination is more streamlined in Malawi, there is no independent ministry of government body responsible for for water quality surveillance. Rural areas in all three countries have fewer financial and technical resources compared to their urban counterparts and have greater challenges related to collecting water quality data, coordinating with national offices, and sharing lessons learned.

After passing the Water Resources Law (LEI № 9.433), Brazil has increased efforts to collect information that can be used for drinking water planning purposes. The Ministry of Cities guides and provides resources (financial or otherwise) for urban planning, including water supply and sanitation. The National Water Agency (ANA) conducted a nation-wide study that resulted in a Water Supply Atlas that consolidates data on water resources and infrastructure needs, by municipality. Water quality data are not included in the Atlas because, despite efforts, the data were not collected and or reported from all municipalities. There are deficiencies in coordination, data sharing and transparency. "Brazil has made significant strides in terms of legislation in the last 20 years, but it has yet to have the desired impact on the ground" (Academic, state management company). "There is a national repository for drinking water quality data, but it is only accessible by a few entities, and data sets are not complete. A great challenge is the lack of strategic planning and coordination at the regional and local levels" (Director for Operations - water utility company).

In Ecuador, collaboration on monitoring and information between government organizations does not occur consistently and this creates water quality surveillance challenges (National MoH employee and SENAGUA officials, Quito, Ecuador). The potential for water quality data sharing and coordination between agencies is great, but currently there is no place or mandate for it (MoH, Quito, Ecuador).

In Malawi, the five water boards have an association of water utilities. They meet four times a year to share best practices and to discuss ways to solve common challenges. Information regarding finances is shared between the Ministry of Irrigation and Water Development.

3.2.2. Monitoring, Enforcement and Surveillance-All three countries have laws that define which government ministry is responsible for monitoring, enforcement and surveillance of water quality; however, these activities are inhibited by insufficient resources and training, especially in rural areas and economically disadvantaged urban areas. Water quality surveillance is the responsibility of the $\mathrm{MoH}$, at the state or department level, in both Brazil and Ecuador, and the World Health Organization guidelines are used as a basis for development of standards. In Malawi, there is no independent surveillance ministry or agency and the Water Boards are responsible for all aspects of monitoring, enforcement and surveillance of drinking water quality. Watershed or catchment area management policies for the protection of source water quality have been incorporated into water policies in all three countries; however, the resources to monitor and enforce policies and the technical capacity to administer them are insufficient (National Water Agency, Brazil; SENAGUA, Ecuador). 
In Brazil, water utilities are required to monitor their own water quality. The $\mathrm{MoH}$ and corresponding state and municipal health departments are responsible for promoting and monitoring water quality compliance. Sampling guidelines are used to determine required levels of monitoring, depending on the population served. Some state and local health agencies do not have enough resources (people and testing equipment) to monitor and enforce the laws as frequently or at as many points along the distribution system as is required, especially in poor or remote areas (advisor to the mayor, state water utility manager, and former employee of the National Water Association).

In Ecuador, monitoring and enforcement of water quality laws to ensure that standards are met was cited as a major challenge. The $\mathrm{MoH}$ is required to conduct surveillance of water quality; however, there are not sufficient resources to monitor and enforce standards. A Provincial MoH water quality technician responsible for water quality testing, stated,

...to give some idea of the great job it is to monitor water quality in [Ecuador, in this province]: the province is divided into 22 health areas. Twelve of the 22 areas are within the provincial capital. Ten are in rural areas. The $\mathrm{MoH}$ has the resources to sample water from some systems, but not all in the province. We have no idea how many systems are treating their water with chlorine in this province... Other provinces have fewer resources than we do. We have more capacity than most other provinces. Testing physical, chemical, and microbiological parameters for one water source costs us $\$ 180-200$. It is not feasible, given our budget, to test water in all water systems. We would also like to be able to test for chemical fertilizers, pesticides and hydrocarbons in some water sources, but this is too expensive and we do not have the proper testing equipment.

In Malawi, The Ministry of Irrigation and Water Development is responsible for policy, regulation, water service provision, and surveillance in urban areas and carries out direct operational monitoring of rural supplies and audits water quality testing of rural Water Boards (Rahman et al, 2011). There is no independent surveillance agency. Water quality provision and monitoring are, therefore carried out by each of the five water boards in urban areas or the district assemblies in rural water; however, there are not sufficient resources to monitor water quality (Water Board representative). The Ministry of Public Health is unable to check water quality because it does not have its own facilities (MOH representative).

3.2.3. Technical Capacity-In all three countries, insufficient technical capacity for water quality testing, especially in rural areas, was mentioned as a major obstacle in the delivery of safe drinking water regularly over time. Decentralization is a key reason that communities are primarily responsible for drinking water supply, maintenance and operation, and water quality monitoring. In all three countries, this responsibility poses a challenge in rural areas and in municipalities or communities that do not have the capacity or the financial resources to address their maintenance and operation needs to treat water, and to monitor water quality so as to meet regulations. Each country, however, has water systems that are known throughout the country as model systems of service delivery.

In Brazil, insufficient technical capacity in monitoring water quality in rural, remote, or economically disadvantaged zones continues to be a challenge (National Water Agency, city 
mayor). A push for investments in infrastructure (focused on network expansion in order to meet the Millennium Development Goals) has increased access to piped water, but the delivery of safe drinking water continues to be a challenge in many areas, especially in water systems that have not been adequately maintained (Mayor and Water Operator).

In Ecuador, municipalities do not have the technical capacity to assist urban and rural service delivery personnel, or implement water quality surveillance throughout the municipality, especially in rural areas, despite being responsible (MIDUVI technicians). A range of water services and water quality surveillance, therefore, exists throughout the country). MIDUVI provides technical assistance to municipalities and is responsible for determining the sector's development strategy, but does not know the number of water systems in the country and does not have the resources to assist all systems (MIDUVI official). The municipality or the CWC is required to register with MIDUVI, however, many have not done so, and this makes it difficult to monitor or assess need.

In Malawi, a variety of problems constrain water boards. "They include: dysfunctional equipment, insufficient staff, lack of technical skills to carry out certain analysis, and inaccessible water sampling points" (Water Board). Chemicals are not always available and sometimes need to be borrowed from other water boards within Malawi, while waiting for the arrival of chemicals from outside the country, like South Africa (Water Board). "Testing water quality often requires the setup costs of a laboratory and water quality testing equipment, and the training of lab technicians. This is feasible in urban areas, but less so in rural areas" (Water Board). In Malawi, in rural areas, water quality surveillance authority rests with the district assemblies, as directed by the 1998 National Policy and 2005 Water Policy. The capacity to monitor and maintain water quality in rural areas is limited by inadequate human and financial capacity (Mulwafu et al, 2003).

3.2.4. Administrative and Technical Management-In Brazil and Ecuador interviews with government officials, operators of water systems, and NGO staff working in the sector revealed that maintenance and operation of water services in the country are inadequate in many dinking water systems ( $\mathrm{MOH}$ and Senagaua, Ecaudor; ANA, Brazil). Reasons cited included: insufficient technical capacity (especially in rural areas) insufficient drinking water treatment oversight and enforcement, and customer nonpayment of water fees.

Challenges for Brazil include, leaky pipes and intermittent service, which are common throughout the country. Financing for repairs in infrastructure are more difficult to find than financing for expansion of services (Water Utility Manager). This lack of maintenance has an impact on water quality throughout the country. Non-paying consumers are a major challenge: revenues from consumer water bills do not fully support operation and maintenance in many systems (water utility companies). Water prices are on a tiered system that is based on consumption; however, little can be done if the consumer does not pay. One state company administrator stated:

... [customers] know there are no real consequences. There is not much we can do. They don't pay, we cut the water, they come and make an agreement to pay, pay the 
first installment (so we will connect them again), then they just stop paying. We cut again, they come back, sign another agreement, we reconnect, and so on. Or they just make an illegal connection. "

Many new investments needed in water systems come from loans or credit from the federal government, which are difficult and time consuming to obtain. There are some older water systems that are not adequately mapped and as systems age, there are fewer and fewer people who know where pipes and valves are located" (Water Utility Manager, Brazil).

In Ecuador, capacity building in operation for water operators is the responsibility of each municipality or community elected water boards, in rural areas. There is not sufficient technical capacity in water treatment (MoH-national and provincial representatives). Furthermore, community water boards are elected for two years, and new board members need training (MoH officials, MIDUVI staff and CEWB).

Operators mentioned a desire to monitor and test water quality in their own systems, but the availability of testing equipment and the capacity to facilitate the tests were cited as obstacles (operators of water systems in North, West and South; MoH and MIDUVI officials). Maintaining residual chlorine in the rainy season because of high turbidity levels is also a challenge (Operator, Central Ecuador). On the coast of Ecuador, water quality issues from the mining of gold and oil are serious concerns; yet, no testing equipment was available for water quality measurement (MIDUVI technician).

In Ecuador, non-payment of water bills hinders maintenance and operation activities in rural and urban areas. Therefore, “...operators are not paid and many water systems are in need of significant repairs” (MIDUVI staff, CEWB president). An NGO manager, and former MIDUVI official, in the coastal region of northwestern Ecuador summarized the problem:

...there is not a culture of paying for the [water] service [by the customers] here [in this province], if it [the water] does not arrive 24 hours a day and is not treated. Some people just don't pay. The law says service can be cut off after 2 months of not paying your water bill, but that doesn't happen in many of the small towns. Everyone knows everyone [in these communities], and it is difficult to cut off someone's water that you know and are friends with or is part of your family.... This means that resources are not available for maintenance, and CWCs have to take out loans to replace pipes, and operators are not adequately compensated for their work."

MIDUVI offers technical assistance in maintenance, trains in administration, and helps with conflict resolution, but the resources are not often available to address all needs (MIDUVI staff in three different provinces). Financial constraints, insufficient technicians, and lack of information on all of the water systems that exist in the country make it difficult to understand the extent of the need (national MIDUVI government official).

In Malawi, lack of financial resources in district assemblies and among water boards limit the maintenance and operation needs that can be addressed, and occasional illegal tapping of water pipes to siphon off water reduce the billable water available in rural areas. Water board officials mentioned consistent resource challenges. "Water pipes are aging, few 
vehicles are available for field visits, and there are too few inspectors" (Water Board). "Vandalism is a problem and pipes are broken to access water during drought periods" (Water Board).

\subsection{The Drinking Water Quality Governance Framework}

From our analysis of the interviews with drinking water quality governance (DWQGo) actors in Brazil, Ecuador and Malawi and interdisciplinary systems thinking, a Drinking Water Quality Governance Framework was created. The common challenges are represented as nodes (identified in the text in the boxes and the text) and the relationships between these nodes are represented with links or arrows. The Framework demonstrates how these challenges are interrelated and eventually impact the delivery of safe drinking water services. The different governance bodies or institutions directly responsible for the specific challenges provide a backdrop (represented in the circles). The challenges or nodes (in Figure 1) can be identified as inputs, processes and outputs. The challenges are linked with arrows to other drinking water service delivery challenges identified in our research. The challenges or nodes identified can also be viewed as policy levers that could be affected to improve drinking water services. The arrows or links in the framework represent feedback loops. Feedback between the different DWQGo sectors of government on the different challenges identified could influence the creation of new policies and standards or modification of existing ones. To create this Framework, first, the common themes (challenges) from the interviews were listed, the levels of government that have power over the different themes in all three countries were then identified in the data. The links and feedback loops were then labeled after the interview data was reanalyzed. A literature review and interdisciplinary systems thinking was used to triangulate the data.

Our Framework represents our findings. The lack of laws and financial capital at the national level directed toward monitoring, enforcement and surveillance of water quality at the state level influences the management of water services at the local level, reduces the information available about drinking water quality, and this in turn effects the technical capacity offered. Inadequate technical capacity in administrative and technical management affects the ability of water service providers to maintain and protect the water system, and treat water. This impacts the quality of the water service provided to the public. Insufficient payment for water services reduces the resources available for administrative and technical management, which in turn reduces resources for operation and maintenance, and ultimately impacts the quality of the drinking water service provided. These nodes or challenges can also be viewed as policy levers. This framework suggests that small adjustments could have important impacts on drinking water quality, with subsequent human health effects on stakeholders.

\section{Discussion}

Our Drinking Water Quality Governance Framework shows actors, inputs, outputs, processes, and their relationships. The framework is heuristic, a starting point for analyzing DWQGo, and a simplified representation of reality. It is not an attempt to accurately mirror every behavior. The Drinking Water Quality Governance Framework represents the 
challenges that were identified by interviewees and how they are interlinked. They are not tested facts, but common challenges identified by those we interviewed.

Our framework suggests that insufficient coordination and data sharing limit the learning potential between different ministries, affects monitoring, enforcement and technical support at the state or district level, which influences the administrative and technical management of services at the local level. Insufficient monitoring, enforcement and surveillance affects the service delivered at the local level. Inadequate technical assistance inhibits the technical and administrative management of water service delivery, ultimately influencing water quality provided to consumers. Addressing some of these challenges may improve learning and create a feedback loop. For example, greater water quality surveillance could improve information about the water systems that are not meeting national water quality standards. Improved technical assistance might assist in identifying specific reasons for which water quality standards are not being met. Through these efforts, the laws and standards at the national level could be enhanced with improved information and data sharing. Improved data sharing and coordination between ministries at the national level could improve monitoring, enforcement and surveillance, which in turn can improve the administrative and technical management of services at the local level. An increase in technical assistance, especially in rural areas, could improve oversight of water quality and could improve the water service delivery managers' attention to water quality.

Conceptual frameworks and empirical studies have provided a basis for analyzing environmental governance (Ostrom, 2011), and have informed frameworks for water governance (Pahl-Wostl et al, 2010; Knieper et al., 2010; Franks and Cleaver, 2007). Franks and Cleaver created a framework to represent water management whereby actors and agents (public officials, political leaders, NGOs, etc.) influence the resources available, which in turn affect access to water. Our framework takes a similar approach but attempts to disaggregate the different levels of government and the types of challenges that might influence resource or power relationships. Kneiper et al (2007) outlined a valuable framework that documented water policy/management processes from goal setting to policy formulation to implementation to monitoring. Our framework builds on this framework by suggesting that technical assistance could be part of this process and lessons learned from monitoring, enforcement, surveillance, and from technical assistance could feedback and inform future policies and standards.

Our framework could be further applied and refined by testing it in other governance and water management settings. Examination of DWQGo across a range of countries can help improve this framework. Research that analyzes other country case studies is needed to discern if similar challenges exist, if the challenges have similar influence on different levels of government, how challenges might affect water service provision (specific outcomes), and the subsequent feedback loops that might occur.

Some research has analyzed specific challenges identified in our research, but no other known research has looked at the different levels of government and the challenges together. In Bolivia, Ghana and Peru, improved technical capacity in administrative and technical management has been suggested to improve the sustainability of drinking water systems 
(Whittington, et al 2009). World Bank research found that the culture of not paying water bills is also a problem in urban areas and even government departments are guilty of nonpayment (WSP, 2006). Others have suggested that improved water governance may contribute to improvements in water service delivery, drinking water quality, and ultimately public and environmental health (Saleth and Dinar, 2000; Livingston, 1995). Our research is the first to look at the governing institutions within the drinking water sector together with the range of challenges faced by different institutions, so that a policy levers can be identified.

There are limitations to this research. The three countries are diverse and only three countries were analyzed in the case study. The framework, policy levers and feedback loops identified in this research should be further tested in other settings. The assumptions identified by interviewees, may not hold true in other contexts, but are interesting in their own right. For example, the assumption that WQ monitoring capacity needs to be created may be abandoned in a place where auditing or third party testing is the norm. Similarly, the assumption that WQ testing is a technical capacity that should be provided by the government may not hold true in countries where it is assumed that supply and demand will sort out the needs for technical capacity. This framework, however, was developed from three case studies with diverse political, economic, social and environmental settings. The incorporation of a country clustering model to select the countries for this study increases its potential for representation and generalizability and decreases the likelihood of selection bias (Geddes, 1990).

The contribution of our research lies within the framework that emerged which points to opportunities that exist for DWQGo. The challenges that were identified by respondents reveal policy levers available to improve water quality and human health. While research on water quality is often focused on specific technical solutions, this research provides an analysis of water governance structures, relationships, and processes that are critical to the delivery of safe drinking water over time.

\section{Conclusions}

Our study identified common challenges in drinking water quality governance (DWQGo) in Brazil, Ecuador, and Malawi. They include: insufficient data sharing and coordination between government offices, lack of monitoring and enforcement of water quality laws, unclear policies from the national government around surveillance of water quality, and administrative and technical management of the water service. Our use of a clustering model for case study selection enhances the generalizability of our results. While each country is unique, our qualitative field research allowed identification of common governance challenges and our analysis produced a framework that allowed us to identify the interconnected nature of the challenges that ultimately influence drinking water quality. The framework maps the relationships among processes, actors, and outcomes of DWQGo, and reveals specific policy levers that could be directed to improve drinking water quality and human health. 


\section{Acknowledgements}

The authors are grateful to government officials, operators and managers of water systems, and NGO representatives throughout Brazil, Ecuador, and Malawi for taking the time to be part of this study, to Professors Richard Andrews and Benjamin Meier for their comments in the development of the semi-structured interviews and the manuscript. Funding for this study was provided by Fogarty International, the National Institute of Health (NIH), Post-Doctoral Fellowship, "Water Wisdom: Developing Local-Global Capacities in Managing Water," (1R24TW008810-01 Bentley-PI).

\section{Bibliography}

1. Agencia Nacional de Aguas. Atlas Brasil. Brasilia: Agencia Nacional de Aguas; 2010.

2. AQUASTAT. [Accessed on -1 August 2012] Water resource information by country/territory and MDG water indicator. FAO-AQUASTAT database. 2012. http://www.fao.org/nr/water/aquastat/ maps/AQUASTAT_water_resources_and_MDG_water_indicator_November_2011.pdf

3. Bakker K, Kooy M, Shofiani NE, Martijn E-J. Governance Failure: Rethinking the Institutional Dimensions of Urban Water Supply to Poor Households. World Development. 2008; 36(10):18911915.Tropical Medicine and International Health. 19(8):884-893.

4. Biswas A, Tortajada C. Future Water Governance: Problems and Perspectives. Water Resources Development. 2010; 26(2):129-139.

5. Clasen T, Pruss-Ustun A, Mathers C, Cumming O, Cairncross S, Colford J. Estimating the impact of unsafe water, sanitation and hygiene on the burden of disease: evolving and alternative methods.

6. Fewtrell L, Kaufmann R, Kay D, Enanoria W, Haller L, Colford J. Water, sanitation and hygiene interventions to reduce diarrhea in less developed countries: a systematic review and meta-analysis. Lancet Infect Dis. 2005; 5:42-52. [PubMed: 15620560]

7. Franks T, Cleaver F. Water governance and poverty: a framework for analysis. Progress in Development Studies. 2007; 7:291-306.

8. Fuest V, Haffner S. PPP-policies, practices and problems. Water Policy. 9(2):169-192.

9. Geddes B. How the Cases You Choose Affect the Answers You Get: Selection Bias in Comparative Politics. Political Analysis. 1990; 2(1):131-150.

10. GWP. Towards water security: a framework for action. Stockholm, Sweden: Global Water Partnership; 2000. Available at: www.gwpforum.org

11. Haller L, Hutton G, Bartram J. Estimating the costs and health benefits of water and sanitation improvements at global level. Journal of Water and Health. 2007; 5(4):467-480. [PubMed: 17878561]

12. Hunter PR, MacDonald AM, Carter RC. Water supply and health. PLoS Med. 2010; 7(11):e1000361. pmid: 21085692. [PubMed: 21085692]

13. Howard G, Bartram J. Effective water supply surveillance in urban areas of developing countries. Journal of Water and Health. 2005; 3(1):31-43. [PubMed: 15952451]

14. Hunter PR, Zmirou-Navier D, Hartemann P. Estimating the impact on health of poor reliability of drinking water interventions in developing countries. The Science of the Total Environment. 2009; 407(8):2621-2464. [PubMed: 19193396]

15. Ison R, Roling N, Watson D. Challenges to science and society in the sustainable management and use of water: investigating the role of social learning. Environmental Science and Policy. 2007; 10(6):499-511.

16. Johnson C, Handmer J. Water Supply in England and Wales: Whose responsibility is it when things go wrong? Water Policy. 2002; 4:345-366.

17. JMP. [Accessed on 15 December 2014] Data Resources and Estimates of the WHO/UNICEF Joint Monitoring Programme for Water Supply and Sanitation. 2014. Available online: http:// www.wssinfo.org/data-estimates/introduction/

18. Knieper C, Holtz G, Kastens C, Pahl Wostl C. Analyzing water Governance in Heterogeneous Case Studies- Experiences with a Database Approach. Environmental Science \& Policy. 2010; 13:592-603. 
19. Lee EJ, Schwab KJ. Deficiencies in drinking water distribution systems in developing countries. Journal of Water and Health. 2005; 3(2):109-127. [PubMed: 16075938]

20. Livingston ML. Designing Water Institutions: Market Failures and Institutional Response. Water Resources Management. 1995; 9:203-220.

21. Mulwafu W, Chipeta C, Chavula G, Ferguson A, Nkhoma B, Chilima G. Water Demand Management in Malawi: Problems and Prospects for its Promotion. Physics and Chemistry of the Earth. 2003; 28:787-796.

22. Onda K, Crocker J, Kayser GL, Bartram J. County Clustering Applied to the Water \& Sanitation Sector: A New Tool With Potential Applications in Research \& Policy. International Journal of Hygiene and Environmental Health. 2014; 217(2-3):379-385. [PubMed: 24054545]

23. Ostrom E. Background on the Institutional Analysis and Development Framework. The Policy Studies Journal. 2011; 39(1):7-27.

24. Pahl-Wostl C, Lebel L, Kneiper C, Nikitina E. From applying panaceas to mastering complexity: Toward adaptive water governance in river basins. Environmental Science and Policy. 2012; 23:24-34.

25. Pahl-Wostl C, Holtz G, Kastens B, Kneiper C. Analzyzing Complex Water Governance Regimes: The Management and Transition Framework. Environmental Science and Policy. 2010; 13(7): 571-581.

26. Pritchard M, Mkandawire T, O’Neill JG. Biological, chemical and physical drinking water quality from shallow wells in Malawi: Case study of Blantyre, Chiradzulu and Mulanje. Physics and Chemistry of the Earth, Parts A/B/C. 2007; 32(15-18):1167-1177.

27. Rahman Z, Crocker J, Chang K, Khush R, Bartram J. A comparative assessment of institutional frameworks for managing drinking water quality. Journal of Water, Sanitation and Hygiene for Development. 2011; 1(4):242.

28. Rizak S, Hrudey S. Drinking-water safety - challenges for community managed systems. Journal of Water and Health. 2008; 6:33-41. [PubMed: 18401127]

29. Rogers, P.; Hall, AW. Effective Water Governance. TEC Background Papers No. 7. Stockholm: Global Water Partnership; 2003.

30. Saleth M, Dinar A. Institutional Changes in Global Water Sector: Trends, Patterns, and Implications. Water Policy. 2000; 2:175-199.

31. Tortajada C. Water Governance: Some Critical Issues. International Journal of Water Resources Development. 2010; 26(2):297-307.

32. Tortajada C. Water Governance: A Research Agenda. International Journal of Water Resources Development. 2010b; 26(2):309-316.

33. Wolf AT, Yoffe SB, Giordano M. International waters : identifying basins at risk. Water Policy. 2003; 5:29-60.

34. UNDP. Fact Sheet No.4: Water and Sanitation Governance, United National Development Programme. 2010

35. Whittington D, Davis J, Prokopy L, Komives K, Thorsten R, Lukacs H, Bakalian A, Wakeman W. How well is the demand driven, community management model for rural water supply systems doing? Evidence from Bolivia, Peru and Ghana. Water Policy. 2009; 11(6):696-718.

36. WSP, Water and Sanitation Program, the World Bank. Getting Africa on Track to Meet the MDGs on Water and Sanitation, A Status Overview of Sixteen African Countries. WSP. 2006 http:// www.wsp.org/wsp/sites/wsp.org/files/publications/ 319200725615_312007101903_MDGs_All_final3_high.pdf.

37. World Bank. [accessed on 5 July 2014] Urban population. United Nations. 2011a. http:// data.worldbank.org/indicator/SP.URB.TOTL.IN.ZS

38. World Bank. [accessed on 5 July, 2014] Government Effectiveness indicators. The World Bank Group. 2011b. http://info.worldbank.org/governance/wgi/index.aspx\#home 


\section{Highlights}

- We analyze drinking water governance challenges in Brazil, Ecuador, and Malawi

- A mixed methods approach was used

- Data sharing, monitoring, enforcement and technical capacity were common challenges

- A conceptual framework identifies policy levers that could address these challenges 


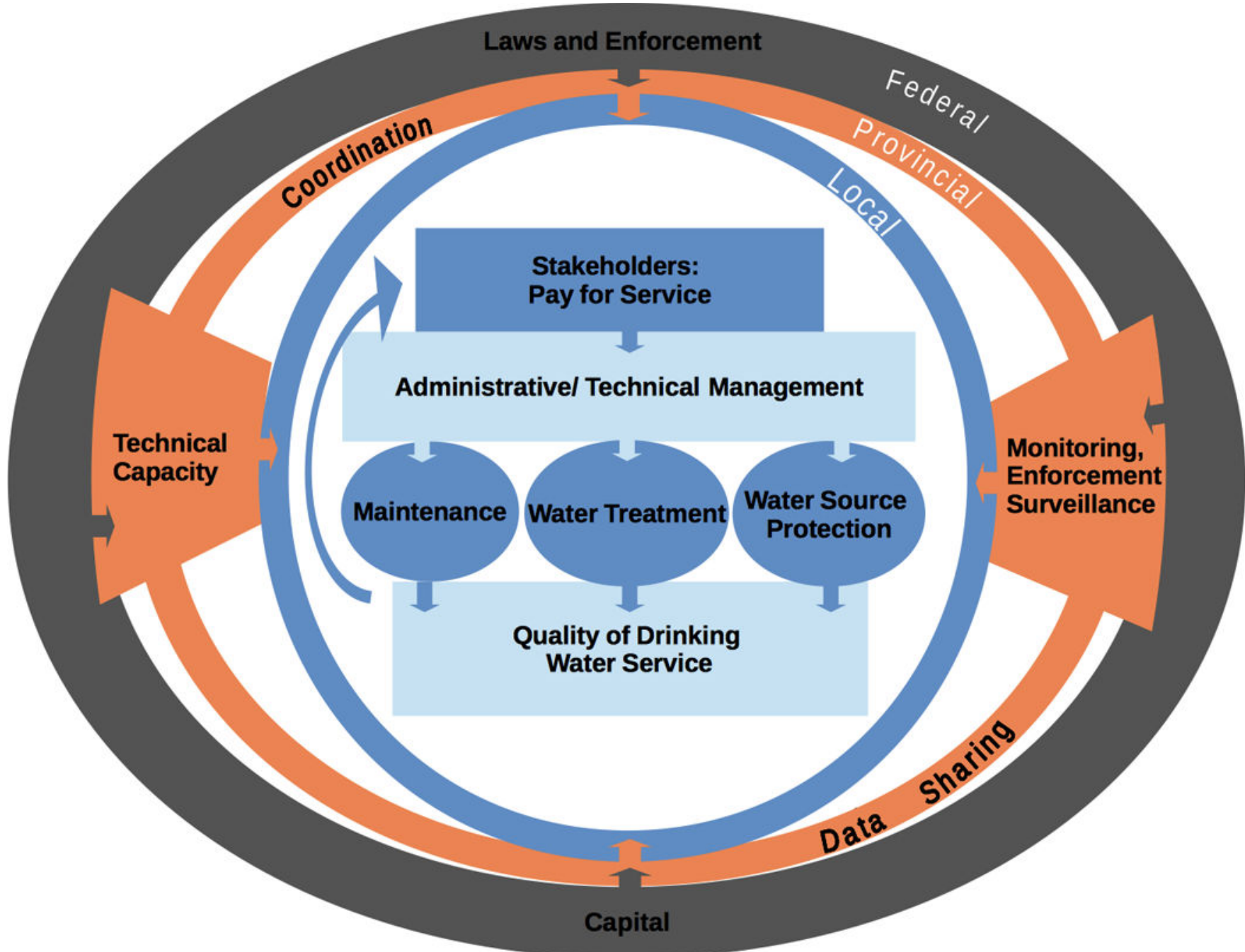

Figure 1.

Diagram of the Drinking Water Quality Governance Framework 
Table 1

Case Study Country Variables in Country Clustering Model

\begin{tabular}{|c|c|c|c|}
\hline & Brazil & Ecuador & Malawi \\
\hline Total Access to Improved Water Supplies (1990) ${ }^{*}$ & $89 \%$ & $74 \%$ & $42 \%$ \\
\hline Total Access to Improved Water Supplies (2010) ${ }^{*}$ & $95 \%$ & $80 \%$ & $63 \%$ \\
\hline Total Access to Improved Sanitation (2010) * & $75 \%$ & $70 \%$ & $10 \%$ \\
\hline Total Available Water Resources $\mathrm{m}^{\wedge} 3 /$ capita/year (2009) $\Phi$ & 42,604 & 29,757 & 1,197 \\
\hline GDP per capita (PPP) $(2011) \$$ & $\$ 11,719$ & $\$ 8,486$ & $\$ 918$ \\
\hline GINI Index $(2009,2010)^{+}$ & 54.7 & $49 / 3$ & 43.9 \\
\hline Expected Years of Schooling (for child of school entrance age) ${ }^{ \pm}$ & 13.8 & 14.0 & 8.9 \\
\hline Percent of Population that is Urban $\mathcal{f}$ & $87 \%$ & $67 \%$ & $20 \%$ \\
\hline Government Effectiveness (ranges from -2.5 (weak) to 2.5 (strong)) $g$ & 0.07 & -0.67 & -0.39 \\
\hline
\end{tabular}

*(JMP, 2014);

$\Phi$ (Aquastat, 2009);

\$(World Bank, 2011a);

${ }^{ \pm}$(UNDP, 2011);

$g_{\text {(World Bank, 2011b); }}$

(World Bank, 2011c),

${ }^{+}$(World Bank, 2010a) 
Table 2

Interview Representatives and Countries of Origin

\begin{tabular}{|c|c|c|c|c|}
\hline Country & $\begin{array}{c}\text { Water Service } \\
\text { Providers }\end{array}$ & Government & $\begin{array}{c}\text { NGOs \& } \\
\text { International } \\
\text { Organizations }\end{array}$ & $\begin{array}{c}\text { Total \# of } \\
\text { Interviews }\end{array}$ \\
\hline Brazil & 5 & 6 & 1 & 12 \\
\hline Ecuador & 15 & 11 & 4 & 30 \\
\hline Malawi & 13 & 4 & 4 & 24 \\
\hline TOTAL & & & & $\mathbf{6 3}$ \\
\hline
\end{tabular}

竞

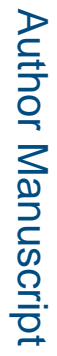

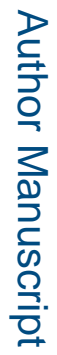

Environ Sci Policy. Author manuscript; available in PMC 2016 April 01. 
Table 3

Laws and policies that govern drinking water quality in Brazil

\begin{tabular}{|l|l|l|}
\hline Laws/Policy & Date & Brief Summary \\
\hline The Brazilian Constitution & & Defines National, State and Local level responsibilities. \\
\hline LEI № 9.433 & 1997 & $\begin{array}{l}\text { Creates the Water Resources Management system, based on the French Model and focused on the } \\
\text { watershed as an administrative unit. Created a National Water Agency (ANA) that is responsible for } \\
\text { water resources planning at the national level. ANA is responsible for providing support to state and } \\
\text { local levels and requires licenses for water withdraws and wastewater discharge. Water allocation is the } \\
\text { responsibility of watershed committees, which are composed of government, stakeholders and civil } \\
\text { society. }\end{array}$ \\
\hline LEI № 11.107 & 2005 & Defines concession rules, and includes public consortia and regional service modalities. \\
\hline LEI № 11.445 & 2007 & $\begin{array}{l}\text { Establishes guidelines for drinking water and sanitation services and a National Directive for Water and } \\
\text { Sanitation Services. Aims to clarify several regulatory aspects of service provision, including the local, } \\
\text { regional and national roles. }\end{array}$ \\
\hline Portaria № 2.914 & 2011 & $\begin{array}{l}\text { Grants the responsibility of “promoting and monitoring compliance” to the Federal Health Secretary and } \\
\text { corresponding State agencies. }\end{array}$ \\
\hline
\end{tabular}




\section{Table 4}

Laws and policy that governs drinking water quality in Ecuador

\begin{tabular}{|l|l|l|}
\hline Laws/Policy & Date & Brief Summary \\
\hline $\begin{array}{l}\text { Ley de Aguas Codificación 16, Registro Oficial } \\
339\end{array}$ & 2004 & $\begin{array}{l}\text { Governs the use of seawater, surface, ground and air of the country, in all its } \\
\text { forms and physical states. }\end{array}$ \\
\hline $\begin{array}{l}\text { Norma Técnica Ecuatoriana NTE INEN 1108 4ta } \\
\text { N. }\end{array}$ & 2006 & Outlines water quality standards in the country. \\
\hline $\begin{array}{l}\text { Ley Orgánica de los recursos hídricos, uso y } \\
\text { aprovechamiento del agua }\end{array}$ & 2008 & $\begin{array}{l}\text { Grants exclusive control of water to the State, which is responsible for its } \\
\text { management, regulation, and control. Makes water a human right for all. }\end{array}$ \\
\hline
\end{tabular}


Table 5

Laws and policies that govern drinking water quality in Malawi

\begin{tabular}{|l|l|l|}
\hline Water Resources Act & $\begin{array}{l}1969, \\
\text { amended in } \\
1996\end{array}$ & $\begin{array}{l}\text { Defines ownership, rights to water, pollution of public water, and establishes gives } \\
\text { responsibility of administration of water resources to Water Resources Boards. }\end{array}$ \\
\hline Malawi Water Works Act & 1995 & $\begin{array}{l}\text { Defines the responsibilities of agencies working in the sector, specifically the water boards, } \\
\text { and provides a legal framework for implementation of integrated water resources } \\
\text { management policy. Water Boards operate under the terms outlined in this Act. }\end{array}$ \\
\hline Water Policy & 2005 & $\begin{array}{l}\text { Outlines an integrated approach to water management. It provides a water management } \\
\text { scheme that is centralized around catchment areas, and assigns roles and responsibilities for } \\
\text { water management. }\end{array}$ \\
\hline Malawi Bureau of Standards, & 2011 & Provides guidance the conduct of water quality sampling programs. \\
\hline
\end{tabular}

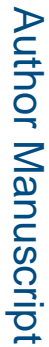

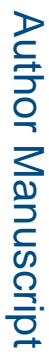

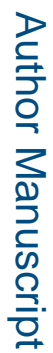

